\title{
Correction to: The tablet computer's impact on learning and National Dental Examination scores in orthodontics - a mixed-method research
}

Thomas Stamm ${ }^{\dagger}$, Irina Triller ${ }^{\dagger}$, Ariane Hohoff and Moritz Blanck-Lubarsch*

\section{Correction to: Head Face Med \\ https://doi.org/10.1186/s13005-019-0195-7}

Following publication of the original article [1], the editor-in-chief reported that the information regarding ethics approval was accidentally entered by the author under trial registration. A trial registration was not required for this study.

Published online: 18 June 2019

\section{Reference}

1. Stamm T, Triller I, Hohoff A, Blanck-Lubarsch M. The tablet computer's

impact on learning and National Dental Examination scores in orthodontics - a mixed-method research. Head Face Med. https://doi.org/10.1186/s13005019-0195-7.

\footnotetext{
* Correspondence: blancklubarsch@uni-muenster.de

${ }^{\dagger}$ Thomas Stamm and Irina Triller contributed equally to this work.

Department of Orthodontics, University of Münster,

Albert-Schweitzer-Campus 1, 48149 Münster, Germany
} 